\title{
Rancang Bangun Sistem Monitoring dan Kontrol Temperatur Pemanasan Zat Cair Menggunakan Sensor Inframerah MLX90614
}

\author{
Tandini Ulfa Urbach*, Wildian \\ Laboratorium Elektronika dan Instrumentasi, Jurusan Fisika, \\ Fakultas Matematika dan Ilmu Pengetahuan Alam, Universitas Andalas \\ Kampus Unand Limau Manis, Padang, 25163, Indonesia \\ *tandini.urbach17@gmail.com
}

\begin{abstract}
ABSTRAK
Telah dirancang sistem monitoring dan kontrol temperatur zat cair menggunakan sensor inframerah MLX90614. Sistem bekerja berdasarkan prinsip penginderaan radiasi inframerah yang dipancarkan objek. Radiasi inframerah yang dindera sensor MLX90614 diubah menjadi sinyal listrik. Sinyal kemudian diolah oleh mikrokontroler yang ada pada modul Arduino Uno R3 dengan bahasa pemrograman IDE Arduino. Hasilnya berupa nilai temperatur yang ditampilkan pada LCD (liquid crystal display). Hotplate dimatikan secara otomatis melalui relay (sebagai saklar on/off) ketika temperatur zat cair mencapai nilai tertentu yang diinginkan. Nilai temperatur acuan diset ke dalam program melalui keypad. Berdasarkan pengujian terhadap sistem yang telah dibangun dan analisis data yang telah dilakukan, dapat disimpulkan bahwa alat dapat mengukur temperatur zat cair secara non-contact dengan akurasi sebesar 99,24\% atau error (ketidaktepatan) sebesar $0,76 \%$ dibanding termometer air-raksa. Nilai tersebut diperoleh dengan kondisi sensor MLX90614 ditempatkan dalam tabung PVC pada jarak $4 \mathrm{~mm}$ dari ujung tabung.

Kata Kunci : hotplate, inframerah, MLX90614, temperatur, zat cair
\end{abstract}

\section{ABSTRACT}

A liquid temperature monitoring and control system has been designed using the infrared sensor MLX90614. The system works based on the principle of sensing of the infrared radiation emitted by the object. Infrared radiation that have sensed by the MLX90614 sensor has converted into an electrical signal. The signal have then processed by the microcontroller in the Arduino Uno R3 module using the Arduino IDE programming language. The processing result have a temperature value that is displayed on LCD (liquid crystal display). The hotplate has automatically turned off via relay (as an on/off switch) when the temperature of the liquid reaches a certain desired value. The reference temperature value has set into the program via the keypad. Based on the testing of the system that has been built and data analysis that has been done, it can be concluded that the tool can measure the temperature of the liquid in a non-contact manner with an accuracy of $99.24 \%$ or an error (inaccuracy) of $0.76 \%$ compared to the mercury thermometers. This value have obtained with the condition that the MLX90614 sensor has placed in a PVC tube (to minimize the effect of radiation from the hotplate) at a distance of $4 \mathrm{~mm}$ from the end of the tube.

Keywords: hotplate, infrared, MLX90614, temperature, liquid

\section{PENDAHULUAN}

Pengukuran temperatur pada zat cair atau larutan banyak dilakukan di laboratorium penelitian, seperti laboratorium kimia dan laboratorium fisika material. Beberapa larutan kimia biasanya memerlukan proses pemanasan terlebih dahulu agar dapat melihat reaksi yang ditimbulkan jika larutan tersebut dipanaskan hingga temperatur terentu. Pengukuran zat cair berdasarkan variasi temperatur biasanya diawali dengan proses pemanasan zat cair menggunakan hotplate. Zat cair dipanaskan hingga mencapai titik didih dan diukur menggunakan termometer. Hal ini cukup menyulitkan karena peneliti tidak dapat memastikan kapan zat cair akan mencapai temperatur yang diinginkan sehingga harus memperhatikan setiap kenaikan dan penurunan temperatur secara terus menerus. Sehingga perlu dibuat sebuah alat yang dapat memonitor perubahan temperatur secara otomatis dan dapat mengontrol pemanasan zat cair hingga temperatur yang diinginkan.

Shidiq dan Rahardjo (2008) telah mengembangkan sistem monitoring untuk temperatur zat cair, khususnya pada air tambak menggunakan sensor LM35. Pengujian sensor temperatur LM35 dilakukan dengan mengukur temperatur air dalam rentang $0{ }^{\circ} \mathrm{C}$ sampai $90{ }^{\circ} \mathrm{C}$. Air pada temperatur $0{ }^{\circ} \mathrm{C}$ dipanaskan perlahan-lahan sampai mencapai temperatur $90{ }^{\circ} \mathrm{C}$, setiap perubahan $5{ }^{\circ} \mathrm{C}$ dicatat temperatur yang terukur pada termometer dan keluaran dari sensor temperatur LM35. Setelah mencapai temperatur $90{ }^{\circ} \mathrm{C}$ air didinginkan perlahan-lahan hingga 
kembali menjadi $15{ }^{\circ} \mathrm{C}$. Nilai error yang diperoleh sensor LM35 dengan alat pembanding yaitu $0,39 \%$. Penggunaan sensor untuk mengukur perubahan temperatur dilakukan secara kontak langsung dengan objek yang dipantau. Cara seperti ini beresiko terhadap kerusakan sensor jika digunakan untuk memantau dan mengontrol temperatur pemanasan zat cair dalam eksperimen di laboratorium.

Jamzuri (2016) menggunakan sensor temperatur LM35 untuk menghasilkan sistem akuisisi data yang user friendly, real time dan akurat sehingga dapat diaplikasikan pada penelitian yang memerlukan data akuisisi pengukur temperatur. Sensor temperatur IC LM35 akan mengirimkan sinyal perubahan temperatur menjadi tegangan listrik $10 \mathrm{mV} /{ }^{\circ} \mathrm{C}$. Selanjutnya tegangan akan dikonversikan oleh ADC (Analog to Digital Converter) pada mikrokontroler ATmega328 (Arduino UNO). Ketika mengukur temperatur air yang dipanaskan temperaturnya terus naik $5{ }^{\circ} \mathrm{C}$ maka pengukuran temperatur dengan LM35 sudah menunjukkan kenaikan temperatur secara linier. Sistem ini dapat memonitoring temperatur zat cair, namun sensor yang digunakan memiliki rentang ukur yang cukup rendah yaitu $-55^{\circ} \mathrm{C}$ sampai $150{ }^{\circ} \mathrm{C}$.

Salah satu jenis sensor yang dapat digunakan untuk memonitoring temperatur yaitu sensor inframerah tipe MLX90614. Sensor MLX90614 adalah sensor temperatur non contact yang mengukur temperatur berdasarkan radiasi inframerah yang dipancarkan oleh suatu objek. Sensor ini dapat mengindera gelombang elektromagnetik di kisaran $700 \mathrm{~nm}$ hingga $14.000 \mathrm{~nm}$ dan dapat mengukur temperatur tubuh manusia dengan akurat pada jarak $5 \mathrm{~cm}$. Sesor MLX90614 dapat mengukur temperatur objek dengan rentang ukur $-70{ }^{\circ} \mathrm{C}$ hingga $380{ }^{\circ} \mathrm{C}$ (Zhang, 2015).

Sensor MLX90614 sebelumnya telah digunakan oleh Simbar dan Syahrin (2017) untuk memonitoring temperatur plate baja. Sensor MLX90614 berfungsi mendeteksi temperatur plate yang ada di lapangan. Prinsip kerjanya adalah mendeteksi pancaran radiasi dari benda uji. Sensor telah dilengkapi dengan ADC sehingga data yang dihasilkan sudah dalam bentuk data digital.

MLX90614 juga pernah digunakan untuk memantau dan mengontrol temperatur oli pelumas pada mesin diesel. Jika oli pelumas bekerja pada temperatur yang terlalu tinggi secara terus menerus maka dapat menyebabkan kualitas oli cepat menurun atau terlalu encer, untuk mengetahui temperatur oli mesin maka operator harus melakukan pengecekan temperatur secara terus menerus setiap satu jam. Berdasarkan hasil perancangan termometer dapat mendeteksi temperatur dengan jarak $0-180 \mathrm{~cm}$. Hasil pengujian dan perbandingan sensor temperatur MLX90614 dengan termostat memiliki selisih rata-rata $0,17^{\circ} \mathrm{C}$ (Huda, 2018).

Penelitian dengan judul rancang bangun sistem kontrol dan monitoring temperatur zat cair menggunakan sensor inframerah MLX90614 diajukan berdasarkan permasalahan yang dihadapi para peneliti yang melakukan penelitian terkait pengaruh perubahan temperatur terhadap zat cair atau larutan. Zat cair dipanaskan menggunakan hotplate hingga mencapai temperatur tertentu. Nilai temperatur yang menjadi acuan dimasukkan melalui keypad dan akan diproses dalam mikrokontroler. Sensor MLX90614 akan memonitoring kenaikan temperatur zat cair yang dipanaskan dan ditampilkan melalui LCD secara real time. Buzzer akan berbunyi sebagai alarm peringatan saat zat cair mencapai temperatur acuan. Hotplate dikontrol melalui relay agar dapat mati secara otomatis apabila pengguna lupa atau tidak mematikannya dalam waktu yang ditentukan.

\section{METODE}

\subsection{Alat dan Bahan}

Alat yang digunakan dalam perancangan ini meliputi Mikrokontroler Arduino Uno R3, modul sensor MLX90614, keypad, relay, LCD, dan buzzer.

\subsection{Perancangan Perangkat Keras Sensor MLX90614}

Rancangan perangkat keras sistem monitoring dan kontrol temperatur pemanasan zat cair menggunakan sensor inframerah MLX90614 adalah seperti Gambar 1. Sistem perangkat keras ini terdiri dari beberapa piranti elektronik yang terhubung langsung dengan 
mikrokontroler Arduino Uno R3 sebagai pusat pengolahan data yang berkaitan dengan input dan output sistem.

Prinsip kerja rancangan perangkat keras ini diawali dengan memasukan nilai temperatur acuan melalui keypad untuk diproses di mikrokontroler. Sensor akan bekerja mengindera besaran fisis intensitas radiasi inframerah zat cair hasil pemanasan oleh hotplate. Saat sensor mendeteksi adanya perubahan temperatur, maka akan diproses oleh Arduino Uno R3 dan LCD akan menampilkan besar nilai temperatur yang terdeteksi. Ketika temperatur telah mencapai nilai temperatur acuan maka buzzer akan berbunyi sebagai pengingat (alarm). LCD akan terus menampilkan nilai temperatur yang terdeteksi oleh sensor secara realtime. Hotplate akan mati secara otomatis jika tidak dimatikan dalam selang waktu yang ditentukan.

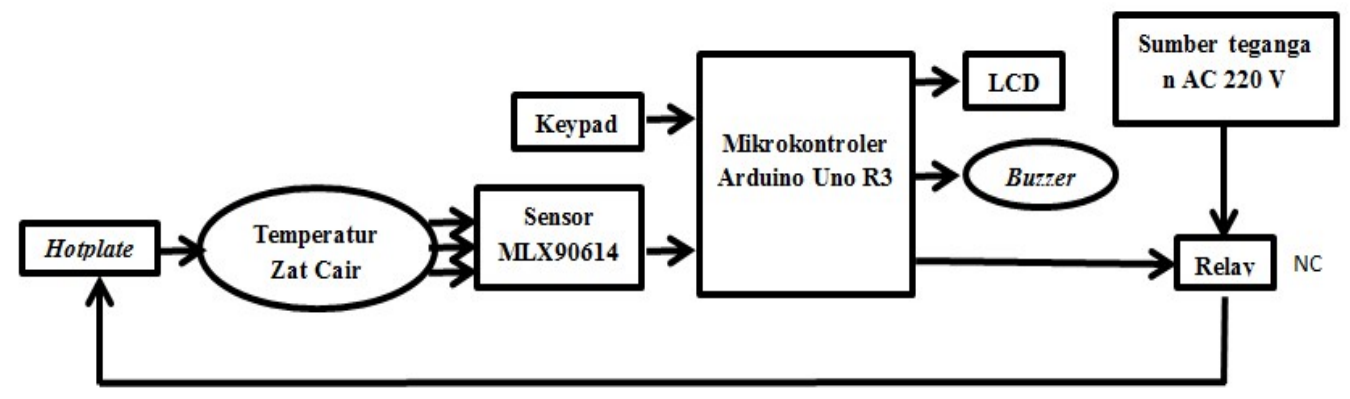

Gambar 4 Diagram blok sistem monitoring dan kontrol temperatur pemanasan zat cair menggunakan sensor inframerah MLX90614

\subsection{Perancangan dan Karakterisasi Sensor MLX90614}

Pengujian sensor MLX90614 dilakukan dengan menggunakan satu buah sensor MLX90614 yang dihubungkan dengan Arduino Uno R3. Rangkaian ini berguna untuk mendeteksi radiasi inframerah yang memiliki panjang gelombang 5,5 $\mu \mathrm{m}$ hingga $14 \mu \mathrm{m}$.

Langkah perancangan sensor yaitu dengan menghubungkan Arduino Uno R3 dengan sensor MLX90614 yang memiliki 4 buah pin yaitu Vin, GND, SCL, SDA. Pin Vin dihubungkan dengan pin 5V pada Arduino Uno R3, pin GND dihubungkan ke GND pada Arduino Uno R3, pin SCL dihubungkan ke A5 pada Arduino Uno R3, dan pin SDA dihubungkan dengan pin A4 Arduino Uno R3. Rangkaian ini dihubungkan ke laptop untuk memonitori perubahan temperatur yang terdeteksi berdasarkan jarak objek dari sensor. Untuk lebih jelasnya dapat dilihat pada Gambar 2.

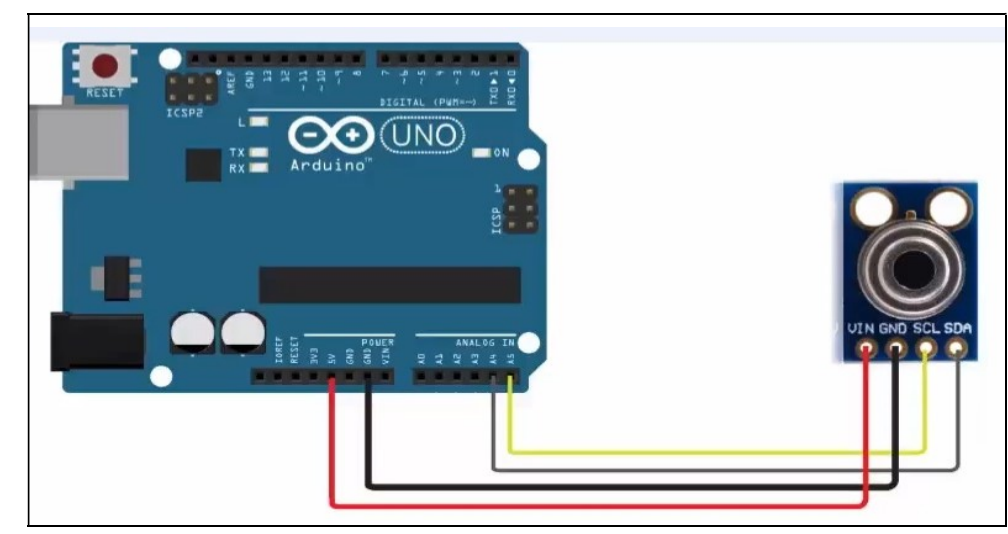

Gambar 5 Skema karakterisasi sensor

\subsection{Perancangan Perangkat Lunak Sistem Sensor}

Sistem instrumentasi yang berbasis mikrokontroler memerlukan urutan instruksi yang disebut program. Flow chart sistem alat monitoring dan kontrol temperatur pemanasan zat cair ini ditulis dalam bahasa pemrograman IDE Arduino. Perancangan perangkat lunak dari alat ini dimulai dari perancangan diagram alir. Perancangan perangkat lunak sesuai dengan prinsip kerja dari sistem yang dibangun. Masukan dari program ini berupa radiasi inframerah yang 
ditangkap oleh sensor inframerah tipe MLX90614. Program dibangun berdasarkan prinsip kerja dari masing-masing komponen yang digunakan, yaitu LCD, I2C, dan buzzer. Berdasarkan prinsip kerja sistem yang direncanakan maka diagram alir program dapat ditampilkan seperti pada Gambar 3.

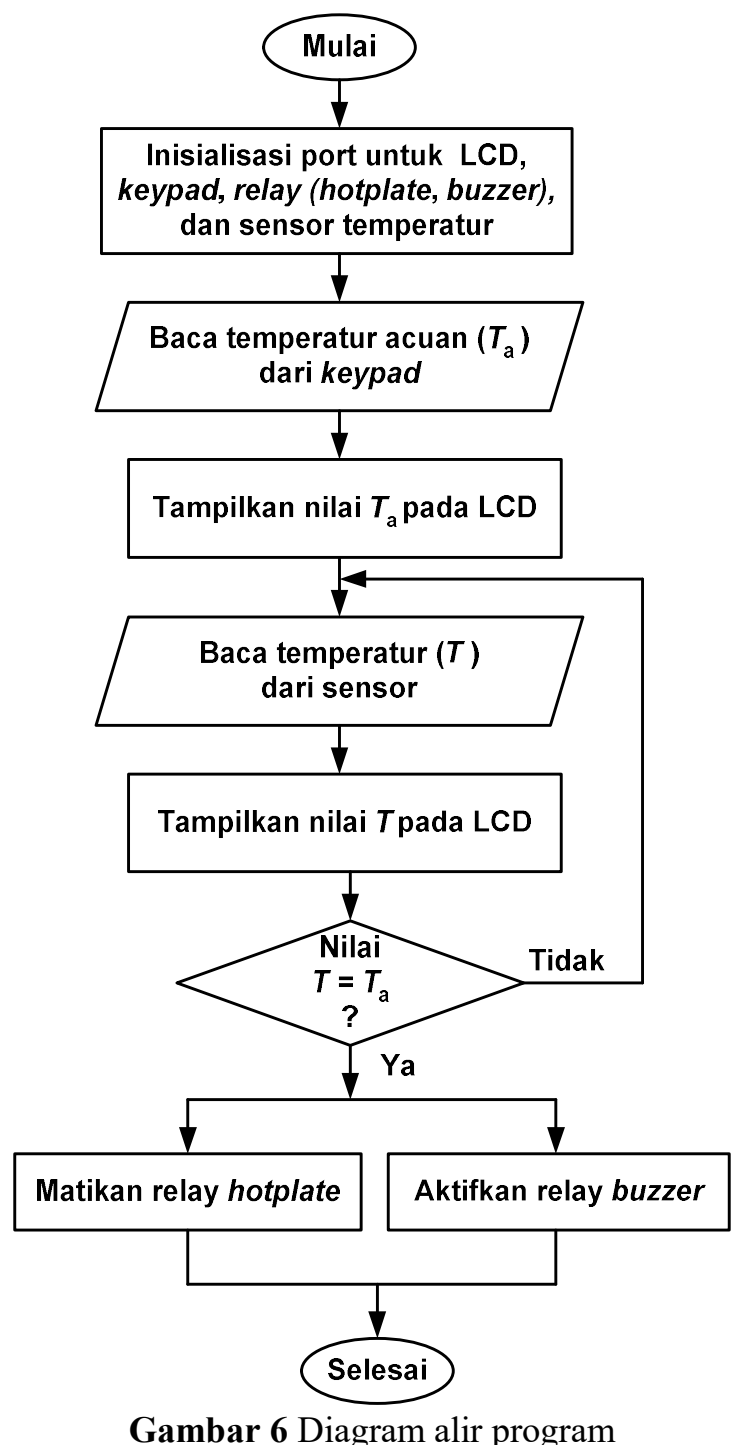

\subsection{Pengujian Sistem dan Pengambilan Data}

Setelah dilakukan pengujian pada masing-masing perangkat input dan output, maka dilakukan pengujian sistem secara keseluruhan, apakah perangkat dapat bekerja dengan baik atau tidak. Pengujian dilakukan dengan cara memanaskan zat cair dalam gelas ukur menggunakan hotplate. Input temperatur yang diinginkan pada keypad agar dapat diproses dalam mikrokontroler. Setiap kenaikan temperatur selama dipanaskan akan ditampilkan secara real-time pada LCD. Setelah sampai pada temperatur yang diinginkan buzzer akan berbunyi sebagai peringatan agar hotplate segera dimatikan. Hotplate juga bisa mati secara otomatis jika tidak dimatikan dalam selang waktu tertentu. Setelah hotplate dimatikan, LCD tetap bisa menampilkan penurunan temperatur yang terdeteksi oleh sensor MLX90614.

Besar persentase kesalahan dalam sistem pengukuran didapatkan melalui Persamaan (1)

$$
\% \text { Error }=\frac{\alpha_{f}-\alpha_{i}}{\alpha_{f}}
$$


Persamaan (1) menunjukkan nilai persentase kesalahan, $\alpha_{\mathrm{f}}$ adalah nilai sebenarnya pada alat pembanding dan $\alpha_{\mathrm{i}}$ adalah nilai yang terbaca pada alat ukur.

\section{HASIL DAN DISKUSI}

Karakterisasi sensor dilakukan untuk mengetahui pengaruh perubahan intensitas inframerah terhadap nilai temperatur yang dihasilkan. Proses karakterisasi sensor MLX90614 dilakukan dengan melakukan beberapa variasi perlakuan sensor, yaitu variasi jarak, posisi sensor, dan variasi penggunaan pelindung.

\subsection{Karakterisasi Sensor MLX90614 dengan Variasi Jarak}

Karakterisasi sensor MLX90614 dengan variasi jarak sensor terhadap objek mulai dari $0 \mathrm{~cm}$ (kontak langsung) sampai $5 \mathrm{~cm}$ pada temperatur sumber yang dibuat tetap $50^{\circ} \mathrm{C}$. Sensor MLX90614 ditempatkan di samping gelas kimia dengan tujuan untuk mengetahui pengaruh jarak terhadap temperatur yang dapat dideteksi dengan benar oleh sensor. Hasilnya menunjukkan bahwa nilai temperatur yang dideteksi sensor semakin kecil dengan bertambahnya jarak, seperti ditunjukan pada Tabel 1. Nilai error terkecil diperoleh pada jarak $1 \mathrm{~cm}$ dan error terbesar diperoleh pada jarak $5 \mathrm{~cm}$. Hal ini menunjukkan bahwa sensor semakin tidak sensitif jika diletakkan semakin jauh dari objek.

Tabel 7 Hasil pengujian sensor MLX90614 pada jarak $1 \mathrm{~cm}$ sampai $5 \mathrm{~cm}$

\begin{tabular}{cccc}
\hline Jarak (cm) & Termometer Air Raksa & Sensor MLX90614 & Error (\%) \\
\hline 1 & 50 & 45,6 & 8,8 \\
2 & 50 & 44,02 & 11,96 \\
3 & 50 & 42,54 & 14,92 \\
4 & 50 & 41,59 & 16,82 \\
5 & 50 & 41,36 & 17,28 \\
\hline
\end{tabular}

\subsection{Karakterisasi Sensor MLX90614 dengan Variasi Posisi Sensor}

Posisi penempatan sensor MLX90614 sangat berpengaruh pada nilai temperatur yang dideteksi alat yang telah dibuat. Variasi posisi sensor yang dilakukan yaitu penempatan sensor di samping gelas kimia dan penempatan sensor di atas permukaan zat cair pada gelas kimia. Hasil pengukuran yang diperoleh dari variasi ini dapat dilihat pada Tabel 2.

Tabel 2 Hasil karakterisasi sensor MLX90614 variasi posisi sensor

\begin{tabular}{cccc}
\hline \multirow{3}{*}{$\begin{array}{c}\text { Jarak } \\
(\mathbf{~ c m})\end{array}$} & $\begin{array}{c}\text { Thermometer } \\
\text { Pembanding } \\
\left({ }^{\circ} \mathbf{C}\right)\end{array}$ & $\begin{array}{c}\text { Sensor Inframerah } \\
\text { MLX90614 } \\
\text { (di samping wadah) } \\
\left({ }^{\circ} \mathbf{C}\right)\end{array}$ & $\begin{array}{c}\text { Sensor Inframerah } \\
\text { MLX90614 } \\
(\text { di atas wadah) } \\
\left({ }^{\circ} \mathbf{C}\right)\end{array}$ \\
\hline & 40 & 38 & 38 \\
1 & 50 & 47 & 46 (rata-rata) \\
& 60 & 55 & 59,5 (rata-rata) \\
& 70 & 63 & 63 (rata-rata) \\
& 80 & 72 & 70,2 (rata-rata) \\
\hline & 40 & 53 & 38 \\
& 50 & 59 & 47 (rata-rata) \\
& 60 & 67 & 56 (rata-rata) \\
& 70 & 76 & 65,2 (rata-rata) \\
& 80 & & 76,5 (rata-rata) \\
\hline
\end{tabular}

Tabel 2 memperlihatkan bahwa pengukuran temperatur dengan variasi posisi sensor di atas wadah menghasilkan pembacaan yang umumnya tidak stabil (mengalami perubahan terus menerus). Hal ini terjadi karena sensor menerima radiasi langsung dari zat cair (tanpa melalui wadah) yang sedang mengalami konveksi (perpindahan kalor secara aliran). Oleh sebab itu, sensor tidak tepat ditempatkan pada posisi di atas wadah, melainkan di samping wadah. 


\subsection{Hasil Karakterisasi Sensor MLX90614 dengan Pelindung dan Tanpa Pelindung}

Penggunaan pelindung berupa pipa plastik berbahan PVC (polyvinyl chloride) pada sensor MLX90614 dan jaraknya dari ujung pelindung ternyata mempengaruhi linieritas dan ketepatan hasil pengukuran, seperti terlihat pada Gambar 4. Pengukuran temperatur dengan sensor tanpa pelindung menghasilkan nilai yang lebih tinggi daripada temperatur yang diukur dengan termometer acuan, dan berlaku untuk semua jarak pengukuran. Hal ini disebabkan adanya pengaruh radiasi dari hotplate dan faktor lingkungan yang turut mempengaruhi hasil pembacaan sensor.

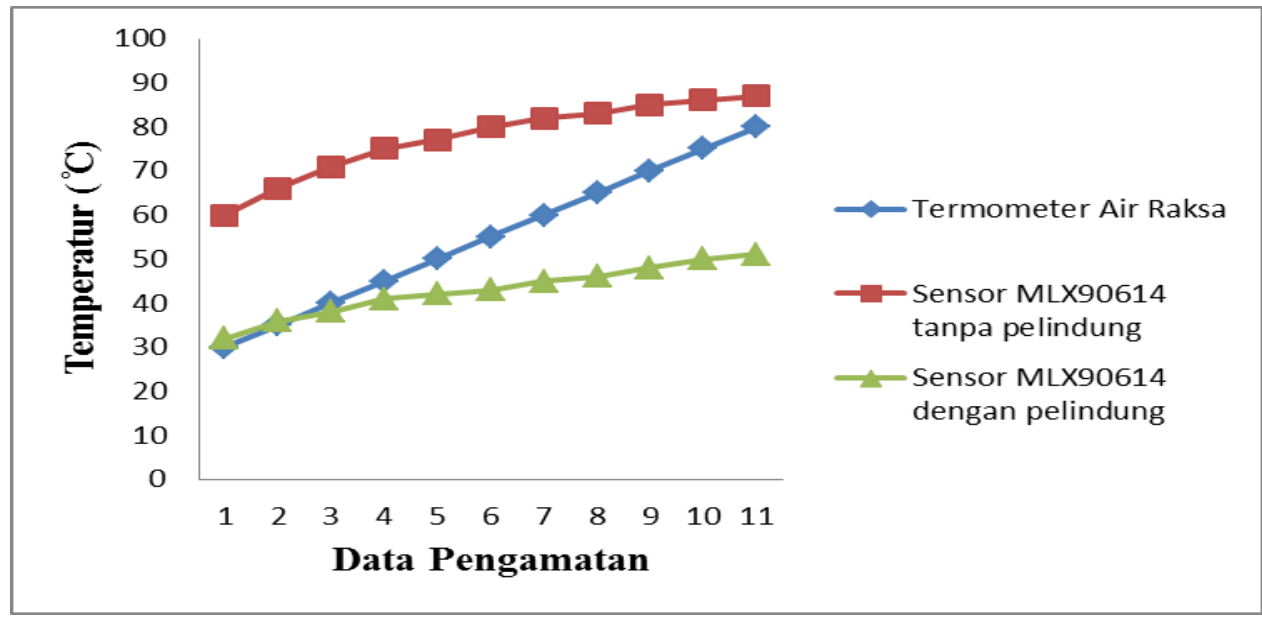

Gambar 4 Hasil pengujian sensor MLX90614 dengan pelindung dan tanpa pelindung pada jarak $4 \mathrm{~cm}$.

Pada pengujian sensor MLX90614 dengan pelindung, data pengukuran yang dihasilkan pada jarak $1 \mathrm{~cm}$ sama seperti pada alat ukur acuan. Pada jarak yang lebih besar, hasil pengukuran cenderung menyimpang makin besar, sepert terihat pada Gambar 5.

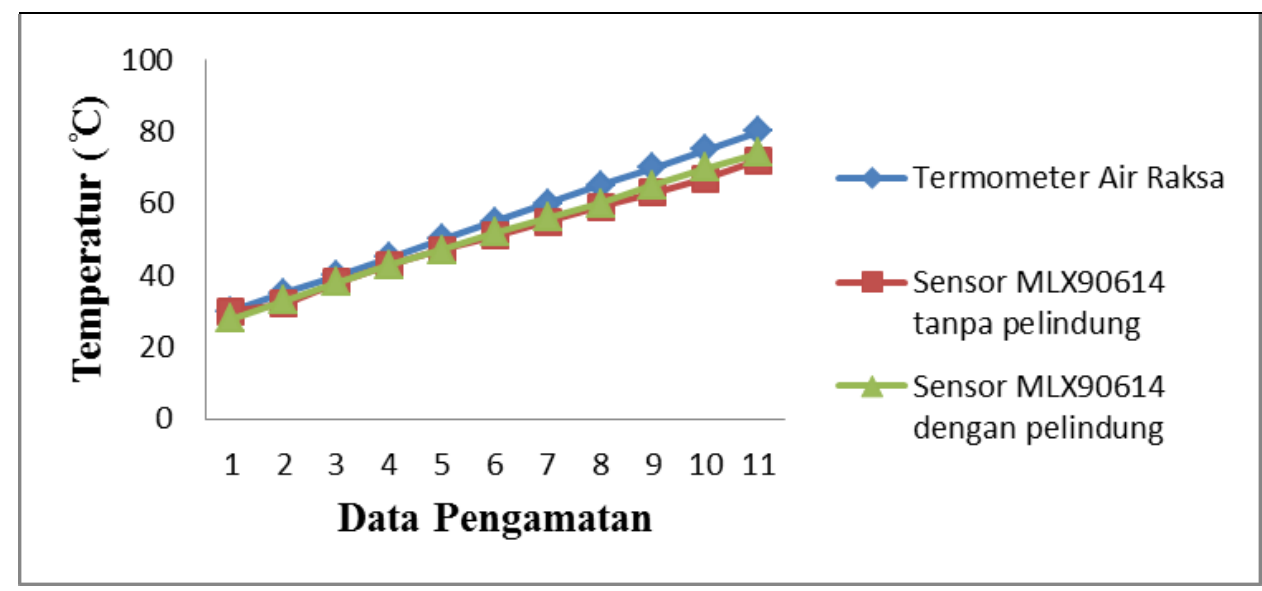

Gambar 5 Hasil pengujian sensor MLX90614 dengan pelindung dan tanpa pelindung pada jarak $1 \mathrm{~cm}$.

Jika sensor ditempatkan pada posisi lebih jauh dari $1 \mathrm{~cm}$, maka diperoleh grafik (baik untuk sensor berpelindung maupun tanpa pelindung) yang memotong grafik yang dihasilkan dari alat ukur acuan, seperti ditunjukkan pada Gambar 6. Penempatan sensor MLX90614 pada jarak $2 \mathrm{~cm}$ menghasilkan data pengukuran yang tidak konsisten, bisa lebih kecil (di bawah nilai yang seharusnya) atau lebih besar (di atas nilai yang seharusnya). 


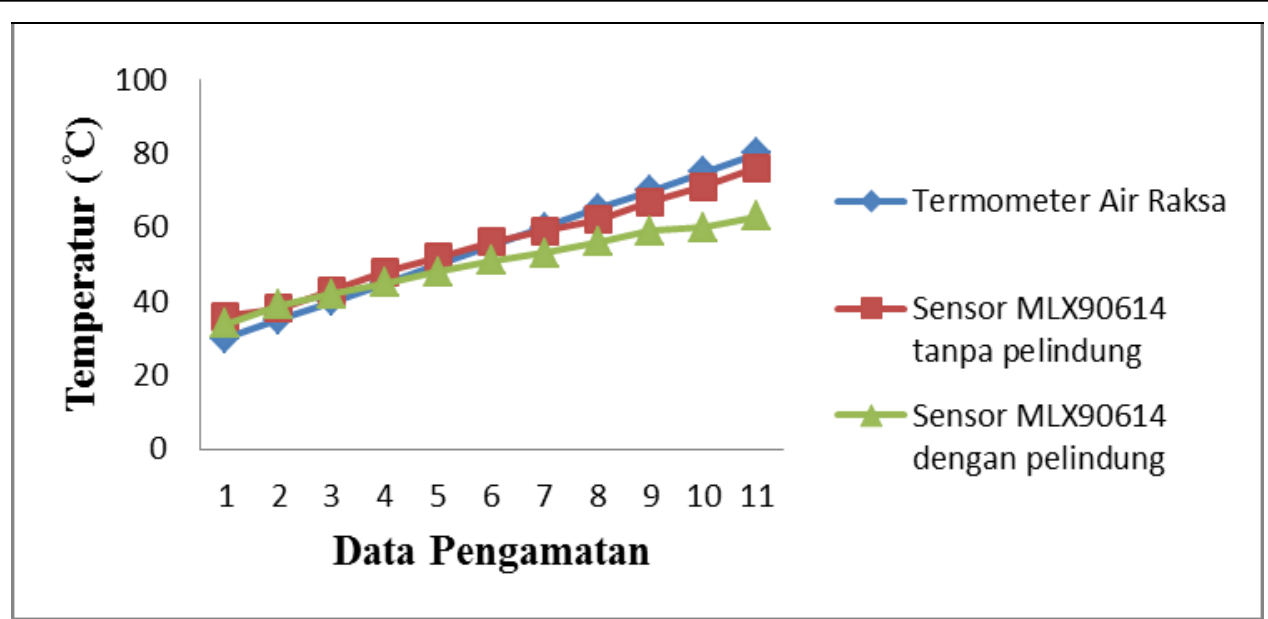

Gambar 6 Pengujian sensor MLX90614 dengan pelindung dan tanpa pelindung pada jarak $2 \mathrm{~cm}$.

Berdasarkan hasil analisis tersebut, sistem sensor kemudian dirancang dengan menempatkan sensor MLX90614 dalam pelindung pada jarak antara 0 hingga $1 \mathrm{~cm}$ dari ujung pelindung.

\subsection{Hasil Pengujian Sensor MLX90614 dengan Pelindung}

Pemilihan jarak sensor dalam pelindung untuk menghasilkan keakuratan yang optimal dilakukan dengan memvariasikan jarak antara 0 dan $1 \mathrm{~cm}$. Dalam hal ini jarak yang diuji adalah $1 \mathrm{~mm}, 2 \mathrm{~mm}, 3 \mathrm{~mm}, 4 \mathrm{~mm}$, dan $5 \mathrm{~mm}$. Hasil perhitungan error diperoleh seperti pada Tabel 3 .

Tabel 3 Pengujian sensor MLX90614 dengan pelindung

\begin{tabular}{|c|c|c|c|c|c|c|c|c|c|c|}
\hline \multirow{2}{*}{$\begin{array}{c}\text { Temperatur } \\
\text { Termometer } \\
\text { Air Raksa }\left({ }^{\circ} \mathrm{C}\right)\end{array}$} & \multicolumn{5}{|c|}{$\begin{array}{c}\text { Jarak / Temperatur Sensor MLX90614 } \\
\left({ }^{\circ} \mathrm{C}\right)\end{array}$} & \multicolumn{5}{|c|}{$\begin{array}{c}\text { Jarak Sensor MLX90614 / } \\
\text { Error (\%) }\end{array}$} \\
\hline & $1 \mathrm{~mm}$ & $2 \mathrm{~mm}$ & $3 \mathrm{~mm}$ & $4 \mathrm{~mm}$ & $5 \mathrm{~mm}$ & $\begin{array}{c}\mathbf{1} \\
\mathbf{m m}\end{array}$ & $\begin{array}{c}2 \\
\mathbf{m m}\end{array}$ & $\begin{array}{c}3 \\
\mathbf{m m}\end{array}$ & $\begin{array}{c}4 \\
\mathbf{m m}\end{array}$ & $\begin{array}{c}\mathbf{5} \\
\mathbf{m m}\end{array}$ \\
\hline 30 & 29,97 & 29,75 & 29,55 & 30,03 & 30,27 & 0,10 & 0,83 & 1,50 & 0,10 & 0,90 \\
\hline 35 & 33,63 & 33,85 & 34,47 & 35,18 & 35,77 & 3,91 & 3,29 & 1,51 & 0,51 & 2,20 \\
\hline 40 & 39,01 & 39,74 & 39,12 & 40,13 & 44,47 & 2,48 & 0,65 & 2,20 & 0,33 & 11,18 \\
\hline 45 & 44,95 & 44,87 & 44,79 & 45,87 & 47,11 & 0,11 & 0,29 & 0,47 & 1,93 & 4,69 \\
\hline 50 & 48,96 & 49,55 & 49,07 & 50,63 & 51,67 & 2,08 & 0,90 & 1,86 & 1,26 & 3,34 \\
\hline 55 & 54,55 & 54,47 & 55,19 & 55,41 & 56,29 & 0,82 & 0,96 & 0,35 & 0,75 & 2,35 \\
\hline 60 & 59,37 & 59,03 & 59,51 & 61,09 & 60,45 & 1,05 & 1,62 & 0,82 & 1,82 & 0,75 \\
\hline 65 & 64,39 & 64,07 & 64,35 & 65,23 & 65,13 & 0,94 & 1,43 & 1,00 & 0,35 & 0,20 \\
\hline 70 & 69,19 & 69,11 & 69,08 & 70,09 & 70,53 & 1,16 & 1,27 & 1,31 & 0,13 & 0,76 \\
\hline 75 & 74,25 & 74,21 & 74,13 & 74,91 & 74,71 & 1,00 & 1,05 & 1,16 & 0,12 & 0,39 \\
\hline 80 & 79,47 & 79,15 & 79,07 & 79,15 & 79,65 & 0,66 & 1,06 & 1,16 & 1,06 & 0,44 \\
\hline \multicolumn{6}{|c|}{ Error Rata - Rata (\%) } & 1,30 & 1,21 & 1,21 & 0,76 & 2,47 \\
\hline
\end{tabular}

Berdasarkan tabel tersebut dapat dilihat bahwa error terkecil diperoleh pada jarak $4 \mathrm{~mm}$ dan error terbesar diperoleh pada jarak $5 \mathrm{~mm}$. Sehingga penempatan sensor dalam pelindung dipilih pada jarak $4 \mathrm{~mm}$ dari ujung tabung karena hasil pengukurannya memiliki akurasi tertinggi, yaitu $99,24 \%$ atau error sebesar $0,76 \%$.

\section{KESIMPULAN}

Berdasarkan pengujian dan analisis yang telah dilakukan, maka dapat disimpulkan bahwa sistem monitoring dan kontrol temperatur zat cair menggunakan sensor inframerah MLX90614 dengan mikrokontroler Arduino Uno R3 sebagai pengendali telah berhasil dirancang bangun dan dapat bekerja dengan baik. Sensor MLX90614 diposisikan pada sisi samping gelas kimia dan ditempatkan dalam wadah pelindung berupa pipa plastik berbahan PVC (polyvinyl chloride) untuk mengurangi pengaruh radiasi hotplate dan faktor lingkungan yang turut mempengaruhi hasil pembacaan sensor. Peletakan sensor terbaik adalah pada jarak 4 
$\mathrm{mm}$ dari ujung pipa karena memiliki linieritas dan ketepatan hasil pengukuran terbaik dengan keakuratan sebesar 99,24\% atau error sebesar 0,76\%. Alat mampu menampilkan hasil pembacaan temperatur pemanasan zat cair secara real time pada LCD, mengaktifkan buzzer untuk menghasilkan bunyi peringatan, dan mematikan hotplate secara otomatis melalui relay ketika zat cair telah mencapai batas temperatur yang diinginkan (nilai batas dimasukkan melalui keypad).

\section{DAFTAR PUSTAKA}

Jamzuri, "Pembuatan Sistem Akuisisi Data Pengukur Temperatur Menggunakan Labview Interface For Arduino (LIFA)", Jurnal Materi dan Pembelajaran Fisika (JMPF) 6(1), 2016.

Huda, D.N. Suryadi, D. dan Hartoyo, A., "Desain Dan Implementasi Non-Contact Thermometer Menggunakan Infrared Untuk Surveillance Berbasis Board Mikrokontroler, Jurnal Teknik Elektro Universitas Tanjungpura 2(1), 2018.

Shidiq, M. dan Rahardjo, P.M., 2008, Pengukur Temperatur dan pH Air Tambak Terintegrasi dengan Data Logger, Jurnal EECCIS 2(1), 2008.

Simbar, R.S.V. dan Syahrin, A., "Prototype Sistem Monitoring Temperatur Menggunakan Arduino Uno R3 Dengan Komunikasi Wireless", Jurnal Teknologi Elektro 8(1), 2017

Zhang, X. Seki, H. dan Hikizu, M., " Detection of Human Detection Position And Motion By Thermopile Infrared Sensor", International Journal of Automation Technology 9(5), 2015. 